\title{
Antimicrobial use for selected diseases in cats in Switzerland
}

\author{
K. Schmitt ${ }^{1,2}$, C. Lehner ${ }^{2,3}$, S. Schuller ${ }^{3}$, G. Schüpbach-Regula ${ }^{4}$, M. Mevissen $^{5}$, R. Peter ${ }^{2}$, C. R. Müntener ${ }^{2}$, \\ H. Naegeli ${ }^{2^{*}}$ and B. Willi $i^{1^{*}}$
}

\begin{abstract}
Background: Antibiotic use in human and veterinary medicine is considered a main driver of antimicrobial resistance. Although guidelines to promote appropriate use of antimicrobials in veterinary patients have been developed, antibiotic overprescription is assumed to be a common problem. The goal of this study was to investigate antimicrobial use in cats in Switzerland with acute upper respiratory tract disease (aURTD), feline lower urinary tract disease (FLUTD) and abscesses, and to assess compliance of prescription with consensus guidelines. A total of 776 cases (aURTD, $n=227$; FLUTD, $n=333$; abscesses, $n=216$ ) presented to two university hospitals and 14 private veterinary practices in Switzerland during 2016 were retrospectively evaluated. Clinical history, diagnostic work-up and antimicrobial prescription (class, dosage, duration) were assessed.
\end{abstract}

Results: A total of 77\% (aURTD), 60\% (FLUTD) and 96\% (abscesses) of the cases received antibiotic therapy; 13-24\% received combination or serial therapy. The cats were treated for a median of 7 (abscesses) and 10 days (aURTD, FLUTD). Treatments with potentiated aminopenicillins (40-64\%), third generation cephalosporins (25-28\%), aminopenicillins (1224\%) and fluoroquinolones (3-13\%) were most common. Prescriptions were judged in complete accordance with consensus guidelines in 22\% (aURTD), 24\% (FLUTD) and 17\% (abscesses) of the cases. Antibiotics were prescribed although not indicated in 34\% (aURTD), 14\% (FLUTD) and 29\% (abscesses) of the cases. The presence of lethargy, anorexia or fever in cats with aURTD, and the detection of bacteriuria in cats with FLUTD were significantly associated with antibiotic therapy. Although diagnostic work-up was significantly more common (aURTD: university hospitals, 58\%; private practices, 1\%; FLUTD: university hospitals, 92\%; private practices, 27\%) and the use of critically important antibiotics significantly less common at the university hospitals (aURTD, 10\%; FLUTD, 14\%) compared to private practices (aURTD, 38\%; FLUTD, 54\%), the frequency of antibiotic treatment was not different between the university hospitals and private practices.

Conclusions: Our results indicate that overprescription of antibiotics in cats in Switzerland is common and accordance with guidelines is poor. The study highlights the need to promote antimicrobial stewardship in small animal medicine.

Keywords: Antibiotic prescription, Antimicrobial stewardship, Resistance, Guidelines, Acute upper respiratory tract disease, Feline lower urinary tract disease, FLUTD, Abscess, Infection

\section{Background}

Mitigation of antimicrobial resistance has been an emerging topic that plays an important role in human and veterinary medicine. Antimicrobial resistance in bacteria is a naturally occurring phenomenon and has been subject to

\footnotetext{
* Correspondence: hanspeter.naegeli@vetpharm.uzh.ch;

bwilli@vetclinics.uzh.ch

${ }^{2}$ Institute of Veterinary Pharmacology and Toxicology, University of Zurich, Winterthurerstrasse 260, CH-8057 Zurich, Switzerland

${ }^{1}$ Clinic for Small Animal Internal Medicine, Vetsuisse Faculty, University of

Zurich, Winterthurerstrasse 260, CH-8057 Zurich, Switzerland

Full list of author information is available at the end of the article
}

evolution over millions of years [1-5]. The frequent use of antimicrobials in human and veterinary medicine and in agriculture exerts an enormous selection pressure on bacterial populations and promotes the development of multidrug-resistant bacteria that can readily spread their resistance genes by various mechanisms [1-3]. Antibiotic use in veterinary medicine is discussed as one of the main drivers for resistance development. In Europe, around 8000 tons of antibiotics were sold for veterinary use in 2015 , with pronounced differences between countries [6]. The amount of antibiotics used in companion animals in Europe in comparison to the amount prescribed in livestock is relatively

(c) The Author(s). 2019 Open Access This article is distributed under the terms of the Creative Commons Attribution 4.0 International License (http://creativecommons.org/licenses/by/4.0/), which permits unrestricted use, distribution, and 
small [6], but is not to be neglected. The close contact of pets with their owners facilitates the transmission of multidrug-resistant organisms between humans and companion animals [1, 7-14]. Furthermore, the trend for intensive medical care of dogs and cats poses a risk for nosocomial infections [15-18] and is associated with an increasing number of geriatric and immunosuppressed patients that are highly susceptible to infections with multidrug-resistant bacteria.

Based on recent data, Centres for Disease Control and Prevention estimates that approximately $30-50 \%$ of antibiotic prescriptions in humans are unnecessary $[19,20]$. Surveys describing antimicrobial use in dogs and cats revealed that antibiotics are frequently prescribed, in particular beta-lactam antibiotics [21-30], and that cats are especially exposed to the critically important third generation cephalosporins [21-25, 30-33]. Most previous studies performed in dogs and cats were based on questionnaires presenting hypothetical scenarios that have been sent out to veterinarians $[22,23,28,33-37]$. These studies are commonly hampered by a selection bias, recall bias and prevarication bias, and the answers given do not necessarily reflect the actual prescribing practice. Some studies analyzed pharmacy records $[38,39]$ and veterinary or pet insurance databases [21, 22, 24-27, 29, 30, 32] but only few studies evaluated whether prescriptions practice was in accordance with relevant guidelines [24, 26, 27, 33, 34].

The aims of this study were to investigate the antimicrobial prescribing practice in Switzerland for indications in cats with frequent use of antibiotics, i.e., in cases of acute upper respiratory tract disease (aURTD), feline lower urinary tract disease (FLUTD) as well as abscesses, and to evaluate to what extend the prescriptions comply with recently established consensus guidelines [40, 41]. The a priori compliance with the proposed guidelines was evaluated in this study to lay the basis to monitor, in a next step, the impact of these guidelines on antimicrobial prescription patterns in Switzerland.

\section{Results}

\section{Case characteristics}

A total of 776 cats were included in the study. Case characteristics are shown in Table 1. A detailed overview of clinical symptoms, diagnostic procedures and antimicrobial prescription for each indication is given in Tables 2, 3 and 4. Cats with aURTD were significantly younger (median age: 3 years) than cats with FLUTD (median age: 8 years, $p<0.001$ ) or cats with abscesses (median age: 7 years; $p<0.001$ ) and more likely to be intact (aURTD and FLUTD: $p<0.001$, aURTD and abscesses: $p<0.001)$. Furthermore, the cats presented to the university hospitals were more often pretreated with antibiotics (aURTD, 30\%; FLUTD, 18\%) and hospitalized (aURTD, 72\%; FLUTD, 69\%) when compared with the cases in private practices (pretreatment: aURTD, 4\%; FLUTD, 2\%; hospitalization: aURTD, 3\%; FLUTD, 15\%). The frequency of antibiotic prescription differed between the indications (percentage of cases treated: aURTD, 77\%; FLUTD, 60\%; abscesses, $96 \% ; p<0.001$ ), but was not significantly associated with breed, age or sex of the cats.

\section{Antibiotic prescription for aURTD}

Of 227 cats with aURTD, 175 (77\%) received antibiotic therapy with the following substance classes: potentiated aminopenicillins (40\%), third generation cephalosporins (28\%), aminopenicillins (24\%), tetracyclines (16\%), fluoroquinolones (4\%), amphenicols (2\%), macrolides (2\%), first generation cephalosporins and penicillins (1\% each); $15 \%$ of the cases received combination or serial therapy. The antimicrobial combinations used were potentiated or non-potentiated aminopenicillins together with fluoroquinolones, first generation cephalosporins, tetracyclines, amphenicols or third generation cephalosporins. One cat received a triple therapy consisting of an aminopenicillin, a fluoroquinolone and a tetracycline. The cats were treated for 4 to 37 days (median of 10 days). Antibiotic therapy was significantly associated with the indications listed in the guidelines (presence of lethargy, anorexia or fever, $p=0.002$ ). The treatment decision was judged as being compliant with the guidelines (justification score-1, JS-1) in 49 cases (22\%) and not in accordance with the guidelines in 135 cases (59\%; JS-2: $n=4,2 \%$; JS-3: $n$ $=48,21 \%$; JS $-4, n=83,36 \%$ ). In the 83 cases where a complete discrepancy with the guidelines was found (JS-4), antibiotic prescription although not indicated (overprescription) occurred in 78 cases $(94 \%)$ whereas 5 cases $(6 \%)$ did not receive antibiotics despite indicated in the guidelines. The lack of information on the presence or absence of disease symptoms as listed in the guidelines precluded judgment in 43 cases (19\%). Judgement of antimicrobial prescription was significantly more often not possible in private practices compared to the university hospitals $(p=$ $0.001)$.

The diagnostic work-up and antimicrobial prescription patterns differed between private practices and university hospitals (Table 2). The aURTD cases were significantly more frequently tested by PCR for the presence of respiratory pathogens at the university hospitals (58\%) compared to private practices (1\%). The choice of antibiotic was significantly more often in disagreement with the guidelines (JS-3) at the university hospitals (61\%) than at the private practices (12\%). This was mainly due to the more common use of potentiated aminopenicillins (university hospitals, 90\%; private practices, 29\%) and the less common use of aminopenicillins (university hospitals, $3 \%$; private practices, $28 \%$ ) at the university hospitals compared to private practices. On the other hand, the use of critically important antibiotics was significantly more common in private practices $(38 \%$; university hospitals, $10 \%$ ). The decision to use antibiotics for 
Table 1 Characteristics of cats with aURTD ${ }^{a}$, FLUTD $^{b}$, and abscesses presented to university hospitals or private practices

\begin{tabular}{|c|c|c|c|c|c|c|c|c|}
\hline \multirow{2}{*}{\multicolumn{2}{|c|}{ Parameter }} & \multicolumn{3}{|l|}{ aURTDa } & \multicolumn{3}{|l|}{ FLUTD $^{b}$} & \multirow{2}{*}{$\begin{array}{l}\text { Abscesses } \\
\text { Private practices }\end{array}$} \\
\hline & & University hospitals & Private practices & $p$-value & University hospitals & Private practices & $p$-value & \\
\hline \multicolumn{2}{|c|}{ Total number of cases } & $n=43$ & $n=184$ & & $n=130$ & $n=203$ & & $n=216$ \\
\hline \multirow[t]{3}{*}{ Sex } & Female & $17(40 \%)$ & $82(45 \%)$ & n.s. ${ }^{c}$ & $43(33 \%)$ & $97(48 \%)$ & 0.006 & $64(30 \%)$ \\
\hline & Male & $24(55 \%)$ & $97(53 \%)$ & & 87 (67\%) & 104 (51\%) & & $148(68 \%)$ \\
\hline & Unknown & $2(5 \%)$ & $5(1 \%)$ & n.a. ${ }^{d}$ & $0(0 \%)$ & $2(1 \%)$ & n.a. $^{d}$ & $4(2 \%)$ \\
\hline Age (years) & Median (range; $\mathrm{Cl}^{e}$ ) & $5(0.042-16 ; 2,9)$ & $2(0.06-19 ; 1,4)$ & n.s. ${ }^{c}$ & $7,(1-21 ; 7,9)$ & $8(0.17-20 ; 6,9)$ & n.s. ${ }^{c}$ & $7(1-18 ; 6,8)$ \\
\hline \multirow[t]{3}{*}{ Breed } & Purebred & $11(26 \%)$ & $33(18 \%)$ & n.s. $^{c}$ & $36(28 \%)$ & $33(16 \%)$ & 0.026 & $14(6 \%)$ \\
\hline & Mixed breed & $29(67 \%)$ & $143(78 \%)$ & & 90 (69\%) & 157 (77\%) & & 190 (88\%) \\
\hline & Unknown & $3(7 \%)$ & $8(4 \%)$ & n.a. ${ }^{d}$ & $4(3 \%)$ & $13(7 \%)$ & n.a. ${ }^{d}$ & $12(6 \%)$ \\
\hline \multirow[t]{3}{*}{ Vaccinated } & Yes & $14(33 \%)$ & $28(15 \%)$ & n.s. ${ }^{c}$ & n.a. $^{d}$ & n.a. ${ }^{d}$ & n.a. ${ }^{d}$ & n.a. ${ }^{d}$ \\
\hline & No & 17 (39\%) & $50(27 \%)$ & & n.a. $^{d}$ & n.a. ${ }^{d}$ & & n.a. $^{d}$ \\
\hline & Unknown & $12(28 \%)$ & $106(58 \%)$ & n.a. ${ }^{d}$ & n.a. ${ }^{d}$ & n.a. ${ }^{d}$ & n.a. ${ }^{d}$ & n.a. ${ }^{d}$ \\
\hline
\end{tabular}

aaURTD, acute upper respiratory tract disease; ${ }^{b}$ FLUTD, feline lower urinary tract disease; ${ }^{c}$ n.s., not significant; ${ }^{d}$ n.a., not applicable; ${ }^{e} \mathrm{Cl}$, confidence interval

Table 2 Diagnostic work-up and antibiotic prescription in aURTDa cases presented to university hospitals or private practices

\begin{tabular}{|c|c|c|c|c|}
\hline Parameter & & University hospitals & Private practices & $p$-value \\
\hline Total number of cases & & $n=43$ & $n=184$ & \\
\hline Diagnostic work-up with $P C R^{b}$ & Yes $^{c}$ & $25(58 \%)$ & $2(1 \%)$ & $<0.001$ \\
\hline \multirow[t]{2}{*}{ At least one of the symptoms listed in the guidelines ${ }^{d}$} & $\mathrm{Yes}^{\mathrm{c}}$ & $29(68 \%)$ & $37(21 \%)$ & $<0.001$ \\
\hline & Unknown & $1(3 \%)$ & $42(23 \%)$ & \\
\hline Hospitalization & $\mathrm{Yes}^{\mathrm{c}}$ & $31(72 \%)$ & $5(3 \%)$ & $<0.001$ \\
\hline \multirow[t]{2}{*}{ Pre-treated with antibiotics } & Yes $^{c}$ & $13(30 \%)$ & $8(4 \%)$ & $<0.001$ \\
\hline & Unknown & $2(5 \%)$ & $4(2 \%)$ & \\
\hline Antibiotic therapy & $\mathrm{Yes}^{\mathrm{c}}$ & $31(72 \%)$ & $144(78 \%)$ & n.s. ${ }^{e}$ \\
\hline \multirow[t]{9}{*}{ Antibiotic classes } & Potentiated aminopenicillins & $28(90 \%)$ & $42(29 \%)$ & $<0.001$ \\
\hline & Third generation cephalosporins & $2(6 \%)$ & 47 (33\%) & 0.002 \\
\hline & Aminopenicillins & $1(3 \%)$ & $40(28 \%)$ & 0.002 \\
\hline & Tetracyclines & $2(6 \%)$ & $26(18 \%)$ & n.s. ${ }^{e}$ \\
\hline & Fluoroquinolones & $1(3 \%)$ & $6(4 \%)$ & n.s. ${ }^{e}$ \\
\hline & Amphenicols & $0(0 \%)$ & $3(2 \%)$ & n.s. ${ }^{e}$ \\
\hline & Macrolides & $0(0 \%)$ & $3(2 \%)$ & n.s. ${ }^{e}$ \\
\hline & First generation cephalosporins & $0(0 \%)$ & $1(1 \%)$ & n.s. ${ }^{e}$ \\
\hline & Penicillins & $0(0 \%)$ & $1(1 \%)$ & n.s. ${ }^{e}$ \\
\hline Combination or serial therapy ${ }^{f}$ & $\mathrm{Yes}^{\mathrm{c}}$ & $4(13 \%)$ & $21(15 \%)$ & n.s. ${ }^{e}$ \\
\hline Critically important antibiotic ${ }^{f}$ & Yes $^{c}$ & $3(10 \%)$ & $55(38 \%)$ & 0.001 \\
\hline Duration of therapy (days) & Median (range) & $12(4-27)$ & $10(4-37)$ & n.s. ${ }^{e}$ \\
\hline \multirow[t]{5}{*}{ Justification score ${ }^{f}$} & 1 & $12(28 \%)$ & $37(20 \%)$ & n.s. ${ }^{e}$ \\
\hline & 2 & $1(2 \%)$ & $3(2 \%)$ & n.s. ${ }^{e}$ \\
\hline & 3 & $26(61 \%)$ & $22(12 \%)$ & $<0.001$ \\
\hline & 4 & $3(7 \%)$ & $80(43 \%)$ & $<0.001$ \\
\hline & Judgement not possible & $1(2 \%)$ & $42(23 \%)$ & 0.001 \\
\hline
\end{tabular}


Table 3 Diagnostic work-up and antibiotic prescription in FLUTDa cases presented to university hospitals or private practices

\begin{tabular}{|c|c|c|c|c|}
\hline Parameter & & University hospitals & Private practices & $p$-value \\
\hline Total number of cases & & $n=130$ & $n=203$ & \\
\hline Urine analysis performed & $Y_{e s}^{b}$ & $119(92 \%)$ & $55(27 \%)$ & $<0.001$ \\
\hline Sediment analysis & $Y_{e s}^{b}$ & $93(72 \%)$ & $50(25 \%)$ & $<0.001$ \\
\hline Bacterial culture & Yes $^{\mathrm{b}}$ & $113(87 \%)$ & $20(10 \%)$ & $<0.001$ \\
\hline Confirmed bacterial etiology ${ }^{c}$ & $Y_{e s}^{b}$ & $45(35 \%)$ & $16(8 \%)$ & $<0.001$ \\
\hline Hospitalization & $Y_{e s}{ }^{b}$ & $90(69 \%)$ & $30(15 \%)$ & $<0.001$ \\
\hline \multirow[t]{2}{*}{ Pre-treated with antibiotics } & $Y_{e s}{ }^{b}$ & $23(18 \%)$ & $4(2 \%)$ & \multirow[t]{2}{*}{$<0.001$} \\
\hline & Unknown & $5(4 \%)$ & $3(2 \%)$ & \\
\hline Antibiotic therapy & Yes $^{\mathrm{b}}$ & $85(65 \%)$ & $115(57 \%)$ & n.s. ${ }^{d}$ \\
\hline \multirow[t]{7}{*}{ Antibiotic classes } & Potentiated aminopenicillins & $71(84 \%)$ & $50(57 \%)$ & $<0.001$ \\
\hline & Third generation cephalosporins & $7(8 \%)$ & $44(38 \%)$ & $<0.001$ \\
\hline & Fluoroquinolones & $5(6 \%)$ & $20(17 \%)$ & 0.017 \\
\hline & Aminopenicillins & $1(1 \%)$ & $22(19 \%)$ & $<0.001$ \\
\hline & First generation cephalosporins & $5(6 \%)$ & $1(1 \%)$ & n.s. ${ }^{d}$ \\
\hline & Amphenicols & $1(1 \%)$ & $0(0 \%)$ & n.s. ${ }^{d}$ \\
\hline & Tetracyclines & $1(1 \%)$ & $0(0 \%)$ & n.s. ${ }^{d}$ \\
\hline Combination or serial therapy ${ }^{e}$ & Yes $^{\mathrm{b}}$ & $6(7 \%)$ & $20(17 \%)$ & n.s. ${ }^{d}$ \\
\hline Critically important antibiotic $^{\mathrm{e}}$ & $Y_{e s}^{b}$ & $12(14 \%)$ & $62(54 \%)$ & $<0.001$ \\
\hline Duration of therapy (days) & Median (range) & $13(1-56)$ & $9(1-42)$ & 0.012 \\
\hline \multirow[t]{5}{*}{ Justification score ${ }^{e}$} & 1 & $57(44 \%)$ & $24(12 \%)$ & $<0.001$ \\
\hline & 2 & $1(1 \%)$ & $0(0 \%)$ & n.s. ${ }^{d}$ \\
\hline & 3 & $22(17 \%)$ & $9(4 \%)$ & $<0.001$ \\
\hline & 4 & $39(30 \%)$ & $11(6 \%)$ & $<0.001$ \\
\hline & Judgement not possible & $11(8 \%)$ & $159(78 \%)$ & $<0.001$ \\
\hline
\end{tabular}

${ }^{a}$ FLUTD, feline lower urinary tract disease; ${ }^{b}$ Values for the category "no" (reference group) are not shown; ${ }^{\mathrm{C}}$ Defined as either positive urine sediment analysis or positive bacterial culture; ${ }^{d}$.s., not significant; ${ }^{e}$ As defined in methods

treatment was significantly more often in disagreement with the guidelines (JS-4) in the private practices (43\%) when compared to the university hospitals $(7 \%)$.

\section{Antibiotic prescription for FLUTD}

Of 333 cats with FLUTD, 200 cases (60\%; 56 with bacterial cystitis, 144 with other/unknown diagnosis) received antibiotic therapy with the following substance classes: potentiated aminopenicillins (61\%), third generation cephalosporins (26\%), fluoroquinolones (13\%), aminopenicillins (12\%), first generation cephalosporins (3\%), amphenicols (1\%) and tetracyclines (1\%); $13 \%$ received combination or serial therapy. For combination therapy, potentiated or non-potentiated aminopenicillins together with fluoroquinolones or third generation cephalosporins were used. The cats were treated for 1 to 56 days (median of 10 days). The presence of bacteriuria was significantly associated with antibiotic therapy $(p<$ $0.001)$. The treatment decision was judged as being compliant with the guidelines (JS-1) in 81 (24\%) and not in accordance with the guidelines in $82(25 \%)$ cases (JS-2: $n=1,1 \%$; JS-3: $n=31,9 \%$; JS-4: $n=50,15 \%)$. In the 50 cases with complete discrepancy to the guidelines (JS-4), antibiotics were prescribed although not indicated (overprescription) in 47 cases (94\%) and cats were not treated with antibiotics despite indicated in the guidelines in 3 cases (6\%). Inadequate diagnostic work-up (154 out of 170 cases, 91\%) was the main reason to preclude judgment in 170 cases (51\%).

Diagnostic work-up and antimicrobial prescription patterns were again different between the university hospitals and private practices (Table 3). Urine sediment analysis or bacterial culture were significantly more commonly performed at the university hospitals (92\%) compared to private practices $(27 \%)$. When antimicrobial prescription at the university hospitals was compared to the private practices, prescription was significantly more often graded as JS-1 (complete agreement with the guidelines; university hospitals, $44 \%$; private practices $12 \%$ ), JS-3 (choice of antimicrobial different from the guidelines; university hospitals, $17 \%$; private practices $4 \%$ ) and JS-4 (complete discrepancy with the guidelines; university hospitals, 30\%; private practices $6 \%$ ). The use of critically important antibiotics was significantly more common in private practices $(54 \%)$ compared to the 
Table 4 Clinical signs, wound treatment and antibiotic prescription in cases with abscesses presented to private practices

\begin{tabular}{|c|c|c|}
\hline \multicolumn{2}{|l|}{ Parameter } & \multirow{2}{*}{$\begin{array}{l}\text { Private practices } \\
n=216\end{array}$} \\
\hline Total number of cases & & \\
\hline \multirow[t]{2}{*}{ At least one of the symptoms listed in the guidelines ${ }^{a}$} & Yes $^{\mathrm{b}}$ & $65(30 \%)$ \\
\hline & Unknown & 85 (39\%) \\
\hline \multirow[t]{2}{*}{ Local wound treatment } & Yes $^{\mathrm{b}}$ & $156(72 \%)$ \\
\hline & Unknown & $12(6 \%)$ \\
\hline Drain placement & Yes $^{\mathrm{b}}$ & $33(15 \%)$ \\
\hline Antibiotic therapy & Yes $^{\mathrm{b}}$ & $207(96 \%)$ \\
\hline \multirow[t]{7}{*}{ Antibiotic classes } & Potentiated aminopenicillins & $132(64 \%)$ \\
\hline & Third generation cephalosporins & $52(25 \%)$ \\
\hline & Aminopenicillins & $50(24 \%)$ \\
\hline & First generation cephalosporins & $12(6 \%)$ \\
\hline & Fluoroquinolones & $5(3 \%)$ \\
\hline & Lincosamides & $4(2 \%)$ \\
\hline & Penicillins & $1(1 \%)$ \\
\hline Combination or serial therapy ${ }^{c}$ & Yes $^{\mathrm{b}}$ & $48(24 \%)$ \\
\hline Critically important antibiotic ${ }^{c}$ & $Y_{e s}^{b}$ & $57(28 \%)$ \\
\hline Duration of therapy (days) & & $7(1-24)$ \\
\hline \multirow[t]{5}{*}{ Justification score ${ }^{c}$} & 1 & $36(17 \%)$ \\
\hline & 2 & $16(7 \%)$ \\
\hline & 3 & $14(7 \%)$ \\
\hline & 4 & 65 (30\%) \\
\hline & Judgement not possible & 85 (39\%) \\
\hline
\end{tabular}

aSigns of generalization, poor general condition, severely contaminated wounds, and/ or proximity to delicate tissues; 'Values for the category "no" (reference group) are not shown; ${ }^{\mathrm{C}} \mathrm{As}$ defined in methods

university hospitals (14\%). Furthermore, judgment of antimicrobial prescription was significantly more often not possible in private practices (78\%; university hospitals, $8 \%)$.

\section{Antibiotic prescription for abscesses}

Of 216 cats with abscesses, 207 cats (96\%) received antibiotic therapy with the following substance classes: potentiated aminopenicillins (64\%), third generation cephalosporins (25\%), aminopenicillins (24\%), first generation cephalosporins (6\%), fluoroquinolones (3\%), lincosamides (2\%) and penicillins (1\%); $24 \%$ received combination or serial therapy. Combination therapy was uncommon (3 cases) and antimicrobial combinations used were potentiated or non-potentiated aminopenicillins together with fluoroquinolones or third generation cephalosporins. The cats were treated for 1 to 24 (median 7) days. Local wound treatment was carried out in 156 of 216 cases (72\%) and drains were placed in 33 of 216 cases (15\%). Antibiotic therapy was not associated with any of the symptoms listed in the guidelines, i.e., signs of generalization, poor general condition, severely contaminated wounds, and/ or proximity to delicate tissues. Antimicrobial therapy was judged in accordance with the guidelines (JS-1) in 36 (17\%) and not in accordance with the guidelines in 95 (44\%) cases (JS-2: $n=$ 16, 7\%; JS-3: $n=14,7 \%$; JS- $4: n=65,30 \%)$. In the 65 cases with complete discrepancy to the guidelines (JS-4), antibiotics were prescribed without indication (overprescription) in 63 cases (97\%) and cats were not treated with antibiotics despite indicated in the guidelines in 2 cases (3\%). Assessment of prudent use was not possible for 85 cases (39\%).

\section{Discussion}

The results of this study indicate that overprescription of antibiotics in cats in Switzerland with aURTD, FLUTD and abscesses is very common. When prescription was compared to the consensus guidelines, $14-34 \%$ of all cases received antibiotics although not indicated; when only the cases were considered for which judgment of prudent use was possible, the rate of antibiotic overprescription was even higher (29-48\%). The diagnostic work-up was more elaborate at the university hospitals, and critically important antibiotics were less commonly prescribed at the universities, but the prudent use pattern of prescriptions was not clearly superior when compared to private practices. This was mainly due to the very common use of potentiated aminopenicillins instead of non-potentiated 
aminopenicillins at the universities. On the other hand, the quality of antimicrobial prescription could often not be judged in the cases from private practices because the diagnostic work-up or the symptoms of the patients were not documented. The common discrepancy of antimicrobial prescription with recently established consensus guidelines $[40,41]$ at the two university hospitals is surprising considering that senior clinicians of these hospitals were involved in the drafting of the guidelines. The overall frequency of antimicrobial treatment was also not different at the university hospitals compared to private practices. However, our data indicates that the animals presented to the university hospitals were more often pretreated or hospitalized, and could thus have been in a more debilitated condition.

Only $17-24 \%$ of the treatment decisions in this study were classified as JS-1 and therefore in complete accordance with the consensus guidelines. Recent studies in dogs and cats have reported an overall agreement of $0-69 \%$ with published guidelines [24, 27, 33, 34]. This overall low accordance raises the question of whether the proposed guidelines cannot be implemented in clinical practice, for example, due to poor market availability of appropriate antibiotic formulations, or whether the content is not well disseminated among veterinary practitioners.

The critically important antibiotics used in cats in this study were mostly third generation cephalosporins as well as fluoroquinolones. Third generation cephalosporins were the second most frequently prescribed antibiotic class and were used in $25-28 \%$ of the cases. This mirrors the results obtained in previous studies [21-25, 31-33] and could likely be explained by the convenient application (as a single subcutaneous injection) and the long dosing interval (2 weeks) of the authorized product in Switzerland (cefovecin, Convenia ${ }^{\circ}$, Zoetis, Delémont, Switzerland). A previous study evaluating electronic health records found that inability to orally medicate the cat was the most common reason given for prescribing cefovecin [42]. An online survey in veterinarians in Switzerland also revealed that the route of application was the most important factor in the choice of antimicrobial therapy in cats [43]. In our study, the prescription of critically important antibiotics was significantly more frequent in private practices compared to the university hospitals. This observation supports the hypothesis that the workplace environment is an important factor determining treatment decisions and antimicrobial use [44]. University hospitals, as training centers, may have stronger restrictions for the use of critically important antibiotics: one of the two university hospitals of this study completely forbids the use of third generation cephalosporins in its patients. On the other hand, the cats at the university hospitals were more commonly hospitalized compared to the cases in private practices, thus allowing for parenteral medication and avoiding the problem of oral application of the antibiotic drug.
Antimicrobial prescription in the absence of proper diagnostic work-up was very common in this study. In only $40 \%$ of the FLUTD cases overall, and in only $10 \%$ of the FLUTD cases in private practices, bacterial culture and susceptibility testing were carried out. In a previous study based on a questionnaire, $32.5 \%$ of companion animal practitioners in Europe reported that they frequently undertake antimicrobial susceptibility testing whereas $9.1 \%$ never demand such tests [45]. In another survey from Italy, $91 \%$ of the practitioners reported to carry out microbiological analysis, although only $20 \%$ reported to do so frequently [35]. Our results indicate that these data based on questionnaires are probably too optimistic and that bacterial culture, an essential diagnostic work-up step for cats with FLUTD, is rarely performed in private practices. In contrast, bacterial culture was performed in $87 \%$ of the FLUTD cases presented to the university hospitals, although this did not result in a less frequent prescription of antimicrobials. Interestingly, 56\% of the FLUTD cases at the universities received antibiotic therapy despite the absence of bacteria in urine culture. A total of $20 \%$ of these cats were pretreated with antibiotics which could have affected the interpretation of a negative bacterial culture result. Also many of these cats suffered from urinary tract obstruction and antibiotic therapy was initiated after removal of the indwelling urinary catheter.

The trend towards more diagnostic testing at the university hospitals is also demonstrated by a more frequent use of PCR for the detection of feline calicivirus (FCV) and feline herpesvirus-1 (FHV) in cases with aURTD. These tests can be useful to support a diagnosis of viral infection and to initiate supportive measures such as the prescription of famciclovir in the case of FHV infection, and thus reduce the use of antibiotics [46]. In this study, the detection of FCV and FHV did not affect the frequency of antibiotic prescription. Overprescription of antibiotics in cats with aURTD was common: although only $29 \%$ of the cats showed symptoms that would have justified an antibiotic therapy according to the consensus guidelines, $77 \%$ of the cases received antibiotic treatment. Potentiated aminopenicillins were most often prescribed at the university hospitals, while third generation cephalosporins and aminopenicillins were most commonly used in private practices. A study revealed that amoxicillin with clavulanic acid is not superior to doxycycline when treating cats with signs of acute respiratory tract disease [47]. Our data, however, indicate that the cases presented to the university hospitals were in a more debilitated condition, because $72 \%$ of the cats with aURTD were hospitalized in comparison to $3 \%$ in private practices. Furthermore, $68 \%$ of the cats presented to university hospitals had symptoms listed in the guidelines, while at the private practices only $21 \%$ of the cats were reported to show a poor general condition, fever, lethargy and/or anorexia. The more compromised clinical 
condition of the patients at university hospitals could explain the common use of potentiated aminopenicillins instead of doxycycline due to the lack of a licensed injectable doxycycline preparation in Switzerland. However, potentiated instead of non-potentiated aminopenicillins were almost exclusively used at the universities. Non-potentiated and potentiated aminopenicillins are often used interchangeably although it has been shown that the use of clavulanic acid may increase AmpC-mediated resistance causing inducible organisms to become insensitive to 1 st to 3 rd generation cephalosporins [48, 49]. The frequent use of potentiated aminopenicillins instead of non-potentiated aminopenicillins in this study could also be due to the better availability of these products on the market, since they make up the largest part of antimicrobial compounds licensed for cats in Switzerland [50].

A total of $96 \%$ of the cats with abscesses received antibiotic treatment but only $30 \%$ of the cats presented symptoms that, according to the guidelines, would justify an antibiotic therapy. Our findings are in line with results from previous studies where frequency of antibiotic prescriptions for skin diseases such as wounds or abscesses ranged from 90 to $97 \%$ [24, 32]. In children, antibiotics might sometimes be applied instead of local wound drainage to avoid anesthesia or sedation [51]. However, $72 \%$ of the cats in this study received local wound treatment and passive drains were placed in $15 \%$ of the cats. It can be assumed that, in many of these cases, antibiotics were supplemented as a preventative measure. Studies from human medicine showed that appropriate drainage of the abscess is important and that antibiotic treatment may not be necessary [52-55]. Several guidelines for small animals state that an antibiotic treatment is not indicated if the abscess is well-defined and the animal is in a good general condition [56-58].

The present study has some limitations. The insufficient documentation in the databases limited the information available for review. The presence of bacteria in urine sediment analysis of an aseptically collected urine sample was considered appropriate to confirm a bacterial etiology in cases with FLUTD, although this is considered insufficient diagnostic work-up according to some guidelines due to the variable quality of interpretation, the risk of stain contamination as well as the possibility of false positive results $[57,59]$. In a recent study, overall accuracy of in-house microscopic evaluation for bacteriuria in primary practice was only $64.5 \%$ when comparing results to reference bacterial cultures [60]. We decided to consider these results since former studies have reported accuracies of urine sediment analysis of $97-98 \%$ when performed by experienced laboratory personal [61-64]. Furthermore, the generally low prevalence of bacterial cystitis in cats should not result in many false positive results [65-67].
The assessment score used in this study leaves a margin of interpretation and the justification of antimicrobial prescription was based on consensus guidelines released in Switzerland. Results could differ to some extent when comparing prescription to guidelines from other countries. Furthermore, the limited number of cases included per practice did also not allow for a statistical analysis at a single practice level. Also, there could be a selection bias since the participation in this study was on a voluntary basis and the enrolled practices might have been more aware of antimicrobial resistance and more likely to prescribe antibiotics prudently.

\section{Conclusions}

The present study highlights the need to promote antimicrobial stewardship in small animal medicine and to implement effective intervention strategies. Particular attention should be paid to the education of veterinarians, the propagation of diagnostic work-up and the need for proper documentation to justify antibiotic treatment. Antimicrobial stewardship at universities should be urgently advanced as they serve as role models for veterinary practice. Developments on the market to provide small spectrum antibiotics for convenient application would be of particular importance in cats since the route of application is a major factor in the choice of antimicrobials in this species. Such new products will contribute to ensure that effective antimicrobials remain available in the future to combat bacterial infections in human and veterinary medicine.

\section{Methods}

Cases presented between January 1st and December 31st 2016 to the two Swiss university teaching hospitals for small animals (Vetsuisse Faculty Bern and Zurich) as well as to fourteen private veterinary practices across Switzerland were included. The private practices participated on a voluntary basis following a nationwide call. In order to identify patients matching the inclusion criteria (Table 5), the electronic records were scanned for predetermined search terms (Table 5) using search functions provided by the particular software. For practical reasons, only private practices using either OblonData ${ }^{\circ}$ (Amacker\&Partner Informatik AG, Zurich, Switzerland) or Diana SUISSE ${ }^{\circ}$ (Diana Software AG, Zurich, Switzerland) were enrolled. A full text search was conducted and the matches were manually reviewed. All cases from the two university hospitals matching the criteria were included. From each private practice, 16 cases per indication that matched the criteria were randomly selected via the sampling function of Microsoft $^{\circ}$ Excel. In the eight private practices where less than 16 cases per indication were found, all cases were included. The number 
Table 5 Inclusion and exclusion criteria and search terms for aURTD ${ }^{a}$, FLUTD ${ }^{b}$ and abscesses

\begin{tabular}{|c|c|c|c|}
\hline Indication & Inclusion criteria & Exclusion criteria & Search terms \\
\hline aURTDa & $\begin{array}{l}\text { Nasal discharge with infectious or unknown } \\
\text { etiology lasting no longer than } 2 \text { weeks }\end{array}$ & $\begin{array}{l}\text { Evidence of fungal infection, } \\
\text { neoplasia or involvement of } \\
\text { the lower respiratory tract }\end{array}$ & $\begin{array}{l}\text { Upper respiratory tract infection, rhinotracheitis, rhinitis, } \\
\text { sinusitis, nasal discharge, sneezing, coughing, stridor, } \\
\text { dyspnea, tachypnea, cat flu, herpes, calici, mycoplasma, } \\
\text { chlamydia, laryngitis }\end{array}$ \\
\hline FLUTD ${ }^{b}$ & $\begin{array}{l}\text { Stranguria, pollakiuria, periuria, pigmenturia } \\
\text { or dysuria and a diagnosis of bacterial cystitis, } \\
\text { bladderstones, urethrastones, urethral plugs, } \\
\text { idiopathic cystitis or cystitis of unknown origin }\end{array}$ & $\begin{array}{l}\text { Involvement of the upper } \\
\text { urinary tract }\end{array}$ & $\begin{array}{l}\text { Lower urinary tract disease, FLUTDb, pollakiuria, } \\
\text { polyuria, anuria, stranguria, dysuria, hematuria, bloody } \\
\text { urine, urinary stones, bladder stones, urolithiasis, } \\
\text { concrements, cystitis, urethra obstruction, urinary tract } \\
\text { infection, UTI, urinary incontinence }\end{array}$ \\
\hline Abscess & Bite abscesses or abscesses of unknown origin & $\begin{array}{l}\text { Anal gland abscesses, tooth } \\
\text { root abscesses, foreign body } \\
\text { abscesses }\end{array}$ & Abscess, bite wound, bite, pus \\
\hline
\end{tabular}

aaURTD, acute upper respiratory tract disease; ${ }^{\mathrm{b}}$ FLUTD, feline lower urinary tract disease

of cases was balanced by limiting the number to 16 per practice to avoid overrepresentation of larger private practices. Although not all cases were included, the random selection should ensure that the results remain representative.

Signalment, vaccination status, clinical history, reports on clinical examination, antibiotic pretreatment, diagnostic work-up, comorbidities, hospitalization and antimicrobial therapy (substance class, dose, frequency of application and duration of therapy) were retrieved from the medical records. The evaluated diagnostic work-up for aURTD included PCR for FCV and FHV; for FLUTD, urine sediment analysis and urine bacterial culture were assessed. Bacteriuria was defined as the presence of bacteria in the urine sediment analysis or in the bacterial culture from an aseptically collected urine sample (cystocentesis or catheterization). Complicated urinary tract infections were defined as infections that were caused by anatomical or functional changes or a comorbidity, that predispose the patient to persistent or recurrent infections or treatment failure [68]. Critically important antibiotics comprised third or higher generation cephalosporins, quinolones, macrolides, ketolides, glycopeptides and polymyxins [69]. Combination therapy was defined as the prescription of two or more antibiotic classes at the same time; serial therapy as the prescription of one antibiotic class followed by a different antibiotic class. Antimicrobial prescription was compared with the consensus guidelines summarized in Table 6 using a previously published JS with modifications shown in Table 7 [70]. The guidelines were published in December 2016 [40] and can be accessed online as the AntibioticScout tool [71]. The present study evaluated antimicrobial prescription prior to the implementation of the guidelines to use this data as a baseline for follow-up studies on the influence of the guidelines on antimicrobial prescription in Switzerland.

For statistical analysis, the commercially available SPSS $^{\odot}$ software (SPSS Inc., IL, USA) was used. Descriptive statistics and comparisons of groups were conducted. Because the continuous variables were not

Table 6 Consensus guidelines $[40,41]$ used to evaluate prudent use of antimicrobials

\begin{tabular}{|c|c|c|c|c|c|}
\hline Indication & Comment & Antibiotic & $\begin{array}{l}\text { Dosage } \\
(\mathrm{mg} / \mathrm{kg})\end{array}$ & $\begin{array}{l}\text { Application } \\
\text { frequency }\end{array}$ & $\begin{array}{l}\text { Treatment duration } \\
\text { (days) }\end{array}$ \\
\hline \multirow[t]{2}{*}{$\overline{\text { aURTD }^{a}}$} & \multirow{2}{*}{$\begin{array}{l}\text { Antibiotic therapy is only indicated if poor general condition, } \\
\text { fever, lethargy and/or anorexia are present }\end{array}$} & Doxycycline & $10 / 5$ & $\mathrm{SID}^{\mathrm{b}} / \mathrm{BID}^{\mathrm{c}}$ & $5-14$ \\
\hline & & Amoxicillin & $15-20$ & $B I D^{c} / T I D^{d}$ & $5-14$ \\
\hline \multirow[t]{4}{*}{ FLUTD $^{\mathrm{e}}$} & \multirow{4}{*}{$\begin{array}{l}\text { Complicated } U \mathrm{TI}^{\mathrm{f}} \text { are defined as infections that are caused by } \\
\text { anatomical or functional changes or disorders of the immune } \\
\text { system }\end{array}$} & $\begin{array}{l}\text { Uncomplicated } \\
\text { UTIf: }\end{array}$ & & & \\
\hline & & Amoxicillin & $11-15$ & $\mathrm{BID} / / \mathrm{TID}^{d}$ & $5-7$ \\
\hline & & Complicated UTIf: & & & \\
\hline & & Amoxicillin/Clavulanic acid & $12.5-20$ & $B I D^{c} / T D^{d}$ & $5-28$ \\
\hline \multirow[t]{5}{*}{ Abscess } & \multirow{5}{*}{$\begin{array}{l}\text { Antibiotic therapy is only indicated if signs of generalization, } \\
\text { poor general condition, severely contaminated wounds, and/ } \\
\text { or proximity to delicate tissues (e.g., joints) are present }\end{array}$} & Amoxicillin & $15-20$ & $\mathrm{BID}^{c}$ & $5-7$ \\
\hline & & Amoxicillin/Clavulanic acid & $12.5-20$ & $B D^{c}$ & $5-7$ \\
\hline & & Cefalexin & $20-30$ & $\mathrm{BID} / / \mathrm{TID}^{d}$ & $5-7$ \\
\hline & & Clindamycin & $10-15$ & $B I D^{c}$ & $5-7$ \\
\hline & & Cefazolin & 20 & $\mathrm{BID}^{c}$ & $5-7$ \\
\hline
\end{tabular}


Table 7 Justification score $\left(J^{\mathrm{a}}\right)$ used to compare antimicrobial prescription to consensus guidelines

\begin{tabular}{ll}
\hline Justification score & Explanation \\
\hline 1 & $\begin{array}{l}\text { Indication, antimicrobial class, dose and treatment } \\
\text { duration in accordance with the guidelines }\end{array}$ \\
& $\begin{array}{l}\text { Antibiotic therapy indicated but duration }{ }^{\mathrm{b}} \text { and/or } \\
\text { dose }^{c} \text { of treatment not in accordance with } \\
\text { the guidelines }^{2}\end{array}$ \\
& $\begin{array}{l}\text { Antibiotic therapy indicated but antimicrobial } \\
\text { class not in accordance with the guidelines }\end{array}$ \\
& $\begin{array}{l}\text { Complete discrepancy with the guidelines, i.e. } \\
\text { antibiotics were prescribed without indication or, } \\
\text { conversely, antibiotics were not prescribed despite } \\
\text { being indicated }\end{array}$ \\
\hline
\end{tabular}

a Modified from De Pestel et al., 2014 [70]; ${ }^{\mathrm{b}} \mathrm{A}$ margin of 1 day shorter or longer was tolerated; ${ }^{\mathrm{C}} \mathrm{A}$ deviation of up to $20 \%$ above or below the recommended dose was accepted; ${ }^{d}$ Each case was scored only once. If the dose or duration of treatment as well as the antibiotic class were deviating from the guidelines, the case was categorized as JS-3

normally distributed, the Mann Whitney U Test was used to compare the median age as well as the duration of therapy between the university hospitals and private practices. For the median age, 95\% confidence intervals (CI) were calculated. The Chi square test was performed for comparison of categorical variables (case characteristics, diagnostic work-up, hospitalization, antibiotic pretreatment and antibiotic prescription) between university hospitals and private practices; frequency of antibiotic therapy between the indications; association of symptoms listed in the guidelines (for aURTD and abscesses) or the presence of bacteriuria (for FLUTD) with antibiotic therapy. The level of significance was set at $p<0.05$. For the comparison of the justification scores between university hospitals and private practices the Chi square test was performed and the significance level was adapted for multiple tests using the Bonferroni correction.

\section{Abbreviations}

aURTD: acute upper respiratory tract disease; BID: twice daily; Cl: confidence interval; FCV: Feline Calicivirus; FHV: Feline Herpesvirus-1; FLUTD: feline lower urinary tract disease; JS: justification score; n.a.: not applicable; n.s.: not significant; PCR: polymerase chain reaction; SID: once daily; TID: three times daily; vs: versus

\section{Acknowledgements}

We thank all private practices and clinics which participated in this study. The authors thank D. Demuth for technical support and helpful discussions. This study was the doctoral thesis of K. Schmitt.

\section{Funding}

This research was supported by the Swiss National Science Foundation (NRP72 grant 407240_167054). The funding body had no role in the design of the study and collection, analysis and interpretation of data and in writing the manuscript.

\section{Availability of data and materials}

The datasets used and analyzed during the current study are available from the corresponding authors on reasonable request.

\section{Authors' contributions}

$\mathrm{HN}, \mathrm{BW}$ and SS conceived the study. BW, SS and RP were responsible for the coordination of the study. CL and KS carried out the data collection. GS was responsible for the statistical analyses. BW and KS drafted the manuscript. $\mathrm{HN}, \mathrm{SS}, \mathrm{MM}, \mathrm{GS}, \mathrm{CL}$ and CRM edited the manuscript. All authors read and approved the final manuscript.

\section{Ethics approval and consent to participate}

All data collected in this study were generated as part of the diagnostic work-up and treatment of the patients. Permissions were obtained to access the data. Formal ethical approval was not required due to the retrospective nature of the study.

\section{Consent for publication}

Not applicable.

\section{Competing interests}

The authors declare that they have no competing interests.

\section{Publisher's Note}

Springer Nature remains neutral with regard to jurisdictional claims in published maps and institutional affiliations.

\section{Author details}

${ }^{1}$ Clinic for Small Animal Internal Medicine, Vetsuisse Faculty, University of Zurich, Winterthurerstrasse 260, CH-8057 Zurich, Switzerland. ${ }^{2}$ Institute of Veterinary Pharmacology and Toxicology, University of Zurich, Winterthurerstrasse 260, CH-8057 Zurich, Switzerland. ${ }^{3}$ Division of Small Animal Internal Medicine, Department of Clinical Veterinary Medicine, Vetsuisse Faculty, University of Bern, Bern, Switzerland. ${ }^{4}$ Veterinary Public Health Institute (VPHI), Vetsuisse Faculty, University of Bern, Bern, Switzerland. ${ }^{5}$ Division of Pharmacology and Toxicology, Vetsuisse Faculty, University of Bern, Bern, Switzerland.

Received: 13 December 2018 Accepted: 25 February 2019

Published online: 14 March 2019

\section{References}

1. Holmes AH, Moore LSP, Sundsfjord A, Steinbakk M, Regmi S, Karkey A, et al. Understanding the mechanisms and drivers of antimicrobial resistance. Lancet. 2016;387:176-87. https://doi.org/10.1016/S0140-6736(15)00473-0.

2. Blair JMA, Webber MA, Baylay AJ, Ogbolu DO, Piddock LJV. Molecular mechanisms of antibiotic resistance. Nat Rev Microbiol. 2015;13:42-51. https://doi.org/10.1038/nrmicro3380.

3. Bhullar K, Waglechner N, Pawlowski A, Koteva K, Banks ED, Johnston MD, et al. Antibiotic resistance is prevalent in an isolated cave microbiome. PLoS One. 2012:7:1-11.

4. Dcosta VM, King CE, Kalan L, Morar M, Sung WWL, Schwarz C, et al. Antibiotic resistance is ancient. Nature. 2011;477:457-61. https://doi.org/10. 1038/nature10388.

5. Hernández J, Stedt J, Bonnedahl J, Molin Y, Drobni M, Calisto-Ulloa N, et al. Human-associated extended-spectrum $\beta$-lactamase in the Antarctic. Appl Environ Microbiol. 2012;78:2056-8. https://doi.org/10.1128/AEM.07320-11.

6. European Medicines Agency, European Surveillance of Veterinary Antimicrobial Consumption 2017. (EMA/184855/2017). Sales of veterinary antimicrobial agents in 30 European countries in 2015. 2017. doi:https://doi. org/10.2809/676974

7. Guardabassi L, Schwarz S, Lloyd DH. Pet animals as reservoirs of antimicrobial-resistant bacteria. J Antimicrob Chemother. 2004;54:321-32. https://doi.org/10.1093/jac/dkh332.

8. Guardabassi L, Loeber ME, Jacobson A. Transmission of multiple antimicrobial-resistant Staphylococcus intermedius between dogs affected by deep pyoderma and their owners. Vet Microbiol. 2004;98:23-7. https://doi. org/10.1016/j.vetmic.2003.09.021.

9. Weese JS, van Duijkeren E. Methicillin-resistant Staphylococcus aureus and Staphylococcus pseudintermedius in veterinary medicine. Vet Microbiol. 2010; 140:418-29. https://doi.org/10.1016/j.vetmic.2009.01.039.

10. Johnson JR, Owens K, Gajewski A, Clabots C. Escherichia coli colonization patterns among human household members and pets, with attention to acute urinary tract infection. J Infect Dis. 2008;197:218-24. https://doi.org/10.1086/524844. 
11. Johnson JR, Johnston B, Clabots CR, Kuskowski MA, Roberts E, DebRoy C. Virulence genotypes and phylogenetic background of Escherichia coli serogroup $\mathrm{O} 6$ isolates from humans, dogs, and cats. J Clin Microbiol. 2008; 46:417-22. https://doi.org/10.1128/JCM.00674-07.

12. Zhang XF, Doi Y, Huang X, Li HY, Zhong LL, Zeng KJ, et al. Possible transmission of mcr-1-harboring Escherichia coli between companion animals and human. Emerg Infect Dis. 2016;22:1679-81. https://doi.org/10. 3201/eid2209.160464.

13. Couto N, Monchique C, Belas A, Marques C, Gama LT, Pomba C. Trends and molecular mechanisms of antimicrobial resistance in clinical staphylococci isolated from companion animals over a 16 year period. J Antimicrob Chemother. 2016;71:1479-87.

14. Paul NC, Moodley A, Ghibaudo G, Guardabassi L. Carriage of methicillinresistant Staphylococcus pseudintermedius in small animal veterinarians: indirect evidence of zoonotic transmission. Zoonoses Public Health. 2011;58: 533-9. https://doi.org/10.1111/j.1863-2378.2011.01398.x.

15. Grönthal T, Moodley A, Nykäsenoja S, Junnila J, Guardabassi L, Thomson K, et al. Large outbreak caused by methicillin resistant Staphylococcus pseudintermedius ST71 in a Finnish veterinary teaching hospital - from outbreak control to outbreak prevention. PLoS One. 2014;9.

16. Grönlund Andersson U, Wallensten A, Hæggman S, Greko C, Hedin G, Hökeberg I, et al. Outbreaks of methicillin-resistant Staphylococcus aureus among staff and dogs in Swedish small animal hospitals. Scand J Infect Dis. 2014:46:310-4. https://doi.org/10.3109/00365548.2013.866267.

17. Leonard FC, Abbott Y, Rossney A, Quinn PJ, O'Mahony R, Markey BK. Methicillin-resistant Staphylococcus aureus isolated from a veterinary surgeon and five dogs in one practice. Vet Rec. 2006;158:155-9. https://doi. org/10.1136/vr.158.5.155

18. Rojas I, Barquero-Calvo E, van Balen JC, Rojas N, Muñoz-Vargas L, Hoet AE. High prevalence of multidrug-resistant community-acquired methicillinresistant Staphylococcus aureus at the largest veterinary teaching hospital in Costa Rica. Vector Borne Zoonotic Dis. 2017;17:645-53. https://doi.org/10. 1089/vbz.2017.2145.

19. Fleming-Dutra KE, Hersh AL, Shapiro DJ, Bartoces M, Enns EA, File TM, et al. Prevalence of inappropriate antibiotic prescriptions among US ambulatory care visits, 2010-2011. JAMA. 2016;315:1864-73. https://doi. org/10.1001/jama.2016.4151.

20. CDC. Antibiotic resistance threats in the United States, 2013. 2013; www. cdc.gov/drugresistance/pdf/ar-threats-2013-508.pdf. Accessed 06 Feb 2019.

21. Singleton DA, Sánchez-Vizcaíno F, Dawson S, Jones PH, Noble PJM, Pinchbeck GL, et al. Patterns of antimicrobial agent prescription in a sentinel population of canine and feline veterinary practices in the United Kingdom. Vet J. 2017;224:18-24. https://doi.org/10.1016/j.tvjl.2017.03.010.

22. Buckland EL, O'Neill D, Summers J, Mateus A, Church D, Redmond L, et al. Characterisation of antimicrobial usage in cats and dogs attending UK primary care companion animal veterinary practices. Vet Rec. 2016;179:489. https://doi.org/10.1136/vr.103830.

23. De Briyne N, Atkinson J, Borriello SP, Pokludov L. Antibiotics used most commonly to treat animals in Europe. Vet Rec. 2014;175:325.

24. Sarrazin S, Vandael F, Van Cleven A, De Graef E, De Rooster H, Dewulf J, et al. The impact of antimicrobial use guidelines on prescription habits in fourteen Flemish small animal practices. VLAAMS Diergeneeskd Tijdschr. 2017:86:173-82.

25. Murphy CP, Reid-Smith RJ, Boerlin P, Weese JS, Prescott JF, Janecko N, et al. Outpatient antimicrobial drug use in dogs and cats for new disease events from community companion animal practices in Ontario. Can Vet J. 2012;53:291-8.

26. Regula G, Torriani K, Gassner B, Stucki F, Müntener CR. Prescription patterns of antimicrobials in veterinary practices in Switzerland. J Antimicrob Chemother. 2009;63:805-11.

27. Escher M, Vanni M, Intorre L, Caprioli A, Tognetti R, Scavia G. Use of antimicrobials in companion animal practice: a retrospective study in a veterinary teaching hospital in Italy. J Antimicrob Chemother. 2011;66:920-7. https://doi.org/10.1093/jac/dkq543.

28. Pleydell EJ, Souphavanh K, Hill KE, French NP, Prattley DJ. Descriptive epidemiological study of the use of antimicrobial drugs by companion animal veterinarians in New Zealand. N Z Vet J. 2012;60:115-22.

29. Thomson KH, Rantala MHJ, Viita-Aho TK, Vainio OM, Kaartinen LA. Condition-based use of antimicrobials in cats in Finland: results from two surveys. J Feline Med Surg. 2009;11:462-6.

30. Hardefeldt LY, Selinger J, Stevenson MA, Gilkerson JR, Crabb H, Billman-Jacobe $\mathrm{H}$, et al. Population-wide assessment of antimicrobial use in dogs and cats using a novel data source - a cohort study using pet insurance data. Vet Microbiol. 2018;225:34-9. https://doi.org/10.1016/J.VETMIC.2018.09.010.

31. Mateus A, Brodbelt DC, Barber N, Stärk KDC. Antimicrobial usage in dogs and cats in first opinion veterinary practices in the UK. J Small Anim Pract. 2011;52:515-21.

32. Radford AD, Noble PJ, Coyne KP, Gaskell RM, Jones PH, Bryan JGE, et al. Antibacterial prescribing patterns in small animal veterinary practice identified via SAVSNET: the small animal veterinary surveillance network. Vet Rec. 2011;169:310. https://doi.org/10.1136/vr.d5062.

33. Van Cleven A, Sarrazin S, de Rooster H, Paepe D, Van der Meeren S, Dewulf J. Antimicrobial prescribing behaviour in dogs and cats by Belgian veterinarians. Vet Rec. 2018;182:324.

34. Hardefeldt LY, Holloway S, Trott DJ, Shipstone M, Barrs VR, Malik R, et al. Antimicrobial prescribing in dogs and cats in Australia: results of the Australasian infectious disease advisory panel survey. J Vet Intern Med. 2017 31:1100-7.

35. Barbarossa A, Rambaldi J, Miraglia V, Giunti M, Diegoli G, Zaghini A. Survey on antimicrobial prescribing patterns in small animal veterinary practice in Emilia Romagna, Italy. Vet Rec. 2017;181:69.

36. Jessen LR, Sørensen TM, Lilja ZL, Kristensen M, Hald T, Damborg P. Crosssectional survey on the use and impact of the Danish national antibiotic use guidelines for companion animal practice. Acta Vet Scand. 2017;59:1-9. https://doi.org/10.1186/s13028-017-0350-8.

37. Hughes LA, Williams N, Clegg P, Callaby R, Nuttall T, Coyne K, et al. Crosssectional survey of antimicrobial prescribing patterns in UK small animal veterinary practice. Prev Vet Med. 2012;104:309-16. https://doi.org/10.1016/j. prevetmed.2011.12.003.

38. Weese JS. Investigation of antimicrobial use and the impact of antimicrobial use guidelines in a small animal veterinary teaching hospital: 1995-2004. J Am Vet Med Assoc. 2006;228:553-8. https://doi. org/10.2460/javma.228.4.553

39. Hölsö K, Rantala M, Lillas A, Eerikäinen S, Huovinen P, Kaartinen L. Prescribing antimicrobial agents for dogs and cats via university pharmacies in Finland-patterns and quality of information. Acta Vet Scand. 2005;46:87-93

40. Peter R, Müntener C, Demuth D, Heim D, Mevissen M, Schüpbach-Regula G et al. AntibioticScout: Online tool for antimicrobial stewardship in veterinary medicine. Schweiz Arch Tierheilkd. 2016;158:805-10. https://doi.org/10. 17236/sat00095

41. Peter R, Demuth D, Müntener C, Lampart M, Heim D, Mevissen M, et al. AntibioticScout.ch: A decision supporting tool for antimicrobial stewardship: application to companion animal medicine. Schweiz Arch Tierheilkd. 2017 159:525-33. https://doi.org/10.17236/sat00129.

42. Burke S, Black V, Sánchez-Vizcaíno F, Radford A, Hibbert A, Tasker S. Use of cefovecin in a UK population of cats attending first-opinion practices as recorded in electronic health records. J Feline Med Surg. 2017;19:687-92. https://doi.org/10.1177/1098612X16656706.

43. Schönenberger AC. Motivation von Kleintierärzten für die Verschreibung von Antibiotika: University of Zurich; 2012.

44. Mateus ALP, Brodbelt DC, Barber N, Stärk KDC. Qualitative study of factors associated with antimicrobial usage in seven small animal veterinary practices in the UK. Prev Vet Med. 2014;117:68-78. https://doi.org/10.1016/j. prevetmed.2014.05.007.

45. De Briyne N, Atkinson J, Pokludová L, Borriello SP, Price S. Factors influencing antibiotic prescribing habits and use of sensitivity testing amongst veterinarians in Europe. Vet Rec. 2013;173:475.

46. Lappin MR, Blondeau J, Boothe D, Breitschwerdt EB, Guardabassi L, Lloyd $\mathrm{DH}$, et al. Antimicrobial use guidelines for treatment of respiratory tract disease in dogs and cats: antimicrobial guidelines working group of the International Society for Companion Animal Infectious Diseases. J Vet Intern Med. 2017;31:279-94. https://doi.org/10. 1111/jvim.14627.

47. Litster AL, Wu CC, Constable PD. Comparison of the efficacy of amoxicillinclavulanic acid, cefovecin, and doxycycline in the treatment of upper respiratory tract disease in cats housed in an animal shelter. J Am Vet Med Assoc. 2012;241:218-26. https://doi.org/10.2460/javma.241.2.218.

48. Jacoby GA. AmpC B-Lactamases. Clin Microbiol Rev. 2009;22:161-82.

49. Kitzis MD, Ferré $B$, Coutrot $A$, Acar JF, Gutmann L. In vitro activity of combinations of beta-lactam antibiotics with beta-lactamase inhibitors against cephalosporinase-producing bacteria. Eur J Clin Microbiol Infect Dis. 1989;8:783-8. 
50. CliniPharm. Institute for Veterinary Pharmacology and Toxicology, Zurich. 2019. https://www.vetpharm.uzh.ch/wir/00002678/7780_f.htm. Accessed 15 Nov 2018.

51. Mistry RD, Shapiro DJ, Goyal MK, Zaoutis TE, Gerber JS, Liu C, et al. Clinical management of skin and soft tissue infections in the U.S. emergency departments. West J Emerg Med. 2014;15:491-8. https://doi.org/10.5811/ westjem.2014.4.20583.

52. Llera JL, Levy RC. Treatment of cutaneous abscess: a double-blind clinical study. Ann Emerg Med. 1985;14:15-9. https://doi.org/10.1016/S01960644(85)80727-7.

53. Rajendran PM, Young D, Maurer T, Chambers $H$, Perdreau-Remington $F$, Ro $P$, et al. Randomized, double-blind, placebo-controlled trial of cephalexin for treatment of uncomplicated skin abscesses in a population at risk for community-acquired methicillin-resistant Staphylococcus aureus infection. Antimicrob Agents Chemother. 2007;51:4044-8. https://doi.org/10.1128/ AAC.00377-07.

54. Hankin A, Everett WW. Are antibiotics necessary after incision and drainage of a cutaneous abscess? Ann Emerg Med. 2007;50:49-51.

55. Duong M, Markwell S, Peter J, Barenkamp S. Randomized, controlled trial of antibiotics in the management of community-acquired skin abscesses in the pediatric patient. Ann Emerg Med. 2010;55:401-7. https://doi.org/10. 1016/J.ANNEMERGMED.2009.03.014

56. Bergvall K, Greko C, Ingman J, Larsson Cl, Mannerfeldt T, Odensvik K, et al. Swedish Veterinary Association Guidelines for the clinical use of antibiotics in the treatment of dogs and cats. 2010. http://www.svf.se/Documents/ S\%C3\%A4llskapet/Sm\%C3\%A5djurssektionen/ Policy\%20ab\%20english\%2010b.pdf

57. Jessen LR, Damborg PP, Spohr A, Schjøth B, Wiinberg B, Houser G, et al. Antibiotic use guidelines for companion animal practice. The Danish Small Animal Veterinary Association, SvHKS, Nov. 2012. https://www.ddd.dk/ sektioner/familiedyr/antibiotikavejledning/Documents/ AntibioticGuidelines\%20-\%20v1.4 jun15.pdf.

58. Holloway S, Trott D, Shipstone M, Barrs V, Malik R, Burrows M. Antibiotic prescribing detailed guidelines. Australasian Infectious Diseases Advisory Panel; 2013. https://www.ava.com.au/sites/default/files/AVA_website/pdfs/ AIDAP\%20prescribing\%20guidelines.pdf.

59. Weese JS, Blondeau JM, Boothe D, Breitschwerdt EB, Guardabassi L, Hillier A, et al. Antimicrobial use guidelines for treatment of urinary tract disease in dogs and cats: antimicrobial guidelines working group of the International Society for Companion Animal Infectious Diseases. Vet Med Int. 2011;2011: 1-9. https://doi.org/10.4061/2011/263768

60. Sørensen TM, Bjørnvad CR, Cordoba G, Damborg P, Guardabassi L, Siersma $V$, et al. Effects of diagnostic work-up on medical decision-making for canine urinary tract infection: an observational study in Danish small animal practices. J Vet Intern Med. 2018;32:743-51.

61. Way LI, Sullivan LA, Johnson V, Morley PS. Comparison of routine urinalysis and urine gram stain for detection of bacteriuria in dogs. J Vet Emerg Crit Care. 2013;23:23-8. https://doi.org/10.1111/vec.12012.

62. O'Neil E, Horney B, Burton S, Lewis PJ, MacKenzie A, Stryhn H. Comparison of wet-mount, Wright-Giemsa and gram-stained urine sediment for predicting bacteriuria in dogs and cats. Can Vet J. 2013; 54:1061-6.

63. Swenson CL, Boisvert AM, Kruger JM, Gibbons-burgener SN. Evaluation of modified Wright-staining for accurate detection of bacteriuria in dogs. J Am Vet Med Assoc. 2004;224:1282-9.

64. Brložnik M, Šterk K, Zdovc I. Prevalence and resistance patterns of canine uropathogens in regard to concurrent diseases. Berl Munch Tierarztl Wochenschr. 2016;129:340-50. https://doi.org/10.2376/00059366-15109.

65. Defauw PA, Van de Maele I, Duchateau L, Polis IE, Saunders JH, Daminet S. Risk factors and clinical presentation of cats with feline idiopathic cystitis. J Feline Med Surg. 2011;13:967-75. https://doi.org/10. 1016/j.jfms.2011.08.001.

66. Kruger JM, Osborne CA, Goyal SM, Wickstrom SL, Johnston GR, Fletcher TF, et al. Clinical evaluation of cats with lower urinary tract disease. J Am Vet Med Assoc. 1991;199:211-6.

67. Buffington CA, Chew DJ, Kendall MS, Scrivani PV, Thompson SB, Blaisdell JL, et al. Clinical evaluation of cats with nonobstructive urinary tract diseases. J Am Vet Med Assoc. 1997;210:46-50.

68. Orenstein R, Wong ES. Urinary Tract Infections in Adults. Am Fam Physician. 1999;59:1225-1234, 1237.
69. World Health Organization. WHO list of critically important antimicrobials for human medicine (WHO CIA list). 2017. http://who.int/foodsafety/ publications/antimicrobials-fifth/en/. Accessed 11 Nov 2018.

70. DePestel DD, Eiland EH, Lusardi K, Destache CJ, Mercier RC, McDaneld PM, et al. Assessing appropriateness of antimicrobial therapy: in the eye of the interpreter Clin Infect Dis. 2014;59(Suppl 3):S154-61. https://doi.org/10.1093/cid/ciu548.

71. AntibioticScout. Institute for Veterinary Pharmacology and Toxicology, Zurich. 2019. http://www.vetpharm.uzh.ch/abscout/. Accessed 15 Nov 2018.
Ready to submit your research? Choose BMC and benefit from:

- fast, convenient online submission

- thorough peer review by experienced researchers in your field

- rapid publication on acceptance

- support for research data, including large and complex data types

- gold Open Access which fosters wider collaboration and increased citations

- maximum visibility for your research: over $100 \mathrm{M}$ website views per year

At $\mathrm{BMC}$, research is always in progress.

Learn more biomedcentral.com/submissions 